\title{
Distributed Democracy: SeeClickFix.com for Crowdsourced issue reporting
}

\author{
Dr. Ines Mergel \\ Assistant Professor of Public Administration and International Affairs \\ Maxwell School of Citizenship and Public Affairs \\ Department of Public Administration and International Affairs \\ Syracuse University \\ 215 Eggers Hall \\ Syracuse, NY 13244 \\ U.S.A. \\ Contact: iamergel@maxwell.syr.edu
}

This document explores one case of the growing Government 2.0 eco-system in the United States of America. SeeClickFix.com (SCF) is a web-based service designed to help citizens report non-emergency issues in their neighborhood. The submissions can be submitted via a web interface, by iPhone, Blackberry and Android reporting apps and a Facebook application. Local government officials receive alerts about submitted issues or can track issues that citizens submitted via the so-called "Watch Area" they are responsible for. The platform allows for direct feedback mechanisms: Local government officials assign a work order number and can change the status of the repair (from open, in progress, to fixed). Citizens are automatically informed about changes in the status of their reported issues allowing for a full feedback cycle. The service is integrated into the social networking services Twitter and Facebook and provides map-based reporting widgets for government and newspaper websites. 


\section{Case Summary}

\begin{tabular}{|c|c|}
\hline Name of the initiative & SeeClickFix.com \\
\hline $\begin{array}{l}\text { Background - short } \\
\text { description }\end{array}$ & $\begin{array}{l}\text { Citizen reporting tool for non-emergency issues in } \\
\text { neighbourhoods with automatic alerts for local } \\
\text { governments to initiate a work process }\end{array}$ \\
\hline $\begin{array}{l}\text { Role of government in the } \\
\text { initiative }\end{array}$ & $\begin{array}{l}\text { Indirect: Governments receive an automated email } \\
\text { alert when an issue is reported and can chose to } \\
\text { respond directly on the SeeClickFix.com platform }\end{array}$ \\
\hline $\begin{array}{l}\text { Business model of the } \\
\text { initiative }\end{array}$ & $\begin{array}{l}\text { Free, Pro (\$40/month), Plus (\$100/month), Connect } \\
\text { models }\end{array}$ \\
\hline Take-up of the service & $\begin{array}{l}\text { Over } 100,000 \text { issues reports, doubled every year, } \\
\sim 10 \% \text { of visitors contribute, available in } 83 \text { languages }\end{array}$ \\
\hline Users' profile & $\begin{array}{l}\text { Target: All users that would like to report an issue; } \\
\text { Majority includes women over } 30 \text { years old }\end{array}$ \\
\hline Barriers and drivers & $\begin{array}{l}\text { Barriers are non-responsive governments } \\
\text { Drivers: Open issues }\end{array}$ \\
\hline $\begin{array}{l}\text { Benefits as seen by the } \\
\text { interviewees }\end{array}$ & $\begin{array}{l}\text { Easy to use tool for low cost on multiple platforms: } \\
\text { Webinterface, mobile phone \& Facebook applications }\end{array}$ \\
\hline Impact on government & $\begin{array}{l}\text { Some local governments respond very positively and } \\
\text { have implemented the service, adopted their own } \\
\text { internal standard operating procedures }\end{array}$ \\
\hline Impact on citizens & $\begin{array}{l}\text { In communities in which local government has } \\
\text { actively adopted SeeClickFix, government reports a } \\
\text { higher degree of happiness, trust and perceived } \\
\text { accountability perceptions among their constituencies. }\end{array}$ \\
\hline Impact on civil servants & $\begin{array}{l}\text { Some civil servants are overwhelmed by unsolicited } \\
\text { emails, while adopters embrace it as the best issue } \\
\text { reporting service out there. }\end{array}$ \\
\hline Accountability issues & $\begin{array}{l}\text { Use increases transparency, efficiency and perception } \\
\text { of accountability, while non-use leads to increased } \\
\text { dissatisfaction with government responsiveness. }\end{array}$ \\
\hline Lessons learnt & $\begin{array}{l}\text { Non-adopters might never change their attitude } \\
\text { towards citizen participation. }\end{array}$ \\
\hline Success indicators & $\begin{array}{l}\text { Numbers of issues reported as of May 9, 2011: } \\
100,000 \text { (doubled every year) }\end{array}$ \\
\hline $\begin{array}{l}\text { Scalability and } \\
\text { sustainability of the } \\
\text { initiative }\end{array}$ & $\begin{array}{l}\text { Cloud service that is hosted on Amazon server with } \\
\text { "unlimited" capacity } \\
\text { Multiple platforms (web interface, mobile, Facebook } \\
\text { applications) } \\
\text { Available in currently } 83 \text { languages } \\
\text { Angel funding of } \$ 1.5 \text { million received, won multiple } \\
\text { awards }\end{array}$ \\
\hline
\end{tabular}




\section{Background of the initiative}

This document explores one case of the growing Government 2.0 eco-system in the United States of America. SeeClickFix.com (SCF) is a web-based service designed to help citizens report non-emergency issues in their neighbourhood. The submissions can be submitted via a web interface, by iPhone, Blackberry and Android reporting apps and a Facebook application. Local government officials receive alerts about submitted issues or can track issues that citizens submitted via the so-called "Watch Area" they are responsible for. The platform allows for direct feedback mechanisms: Local government officials assign a work order number and can change the status of the repair (from open, in progress, to fixed). Citizens are automatically informed about changes in the status of their reported issues allowing for a full feedback cycle. The service is integrated into the social networking services Twitter and Facebook and provides map-based reporting widgets for government and newspaper websites.

Ben Berkowitz, the co-founder and CEO, had the initial idea for the service in 2007 and officially launched the platform in 2008. In his words, the motivation to create the service was a lack of responsiveness of his own local government in New Haven, CT:

"So there was graffiti in my neighbor's building next door to my house, and when I went to talk to my neighbor I had some trouble approaching him to remove it. And when I tried to call local government here in New Haven Connecticut, I had some trouble getting response from them. And so while waiting on hold for a city employee I thought, you know, I bet that other people have documented the same issue as me, by calling into this black box in City Hall, and there's no record of it, and it'd be great if we could make this public. And so we sat down at the weekend, we spent 4 hours and we made a little Google map that'll ask people to publicly document issues in their community, And then we went and created a tool called the Watch Area which was the ability for governments and others to receive alerts on the things that were happening within their geography."

Ben Berkowitz, Co-founder of SeeClickFix.com 


\section{Citizen needs}

As Ben Berkowitz described in his statement above, the main need that is met with SeeClickFix.com is to alert governments of issues that need to be fixed in the community. These issues include potholes, graffiti, broken infrastructure, like roads, street lights or sidewalks, flooding, needs for improvements around pedestrian, cycling, or transportation infrastructure, or beautification projects around parks, but also trash removal, parking in bikes lanes, etc.

While reporting and alerting local government about non-emergency issues is an established communication channel in the U.S., it is mostly done via direct phone calls or email submission forms on a local government website. Most of the time, government does no send a response back to citizens and it is oftentimes unclear if an issue has been take care of or is still open. This disconnect - between citizen needs and government action - results in a one-directional reporting with no feedback mechanisms. Many citizens describe issue reporting therefore as a "black box". SeeClickFix set out to address this issue, to depict reported issues in a transparent way on a Google Map mash-up. Beyond reporting, SCF also allows local government officials to report fixed issues with the goal to potentially increase their own accountability and responsiveness. Moreover, SCF helps governments to integrate their work order system with SCFs reporting system on the backend (available only for Pro Users).

\section{Inspiration for the project and comparable services}

The initial idea was developed by Ben Berkowitz and his co-founder, and as he said: "We looked at Fix My Street [in the UK] after we got the idea, because we heard that we were doing similar things to what we wanted to do. And we looked at 
the code and decided we were gonna just do it on our own, and base it on top a Google Maps. Difference to FixMyStreet: alerts can be sent to anybody so, it's not just governments that are helping us fix problems on SeeClickFix."

The New York Times reports, "SeeClickFix is not unique in its hyperlocal focus. Other sites, like EveryBlock.com and CrimeReports.com, post data from government organizations and news outlets. FixMyStreet.com features discussion between residents and government officials, but only in Britain". ${ }^{i}$ Nevertheless, SCFs does have the unique ability to provide updates based on zip codes on a Google Map that are not restricted to the US. Users can set customizable watch areas (see the read area on the map below):

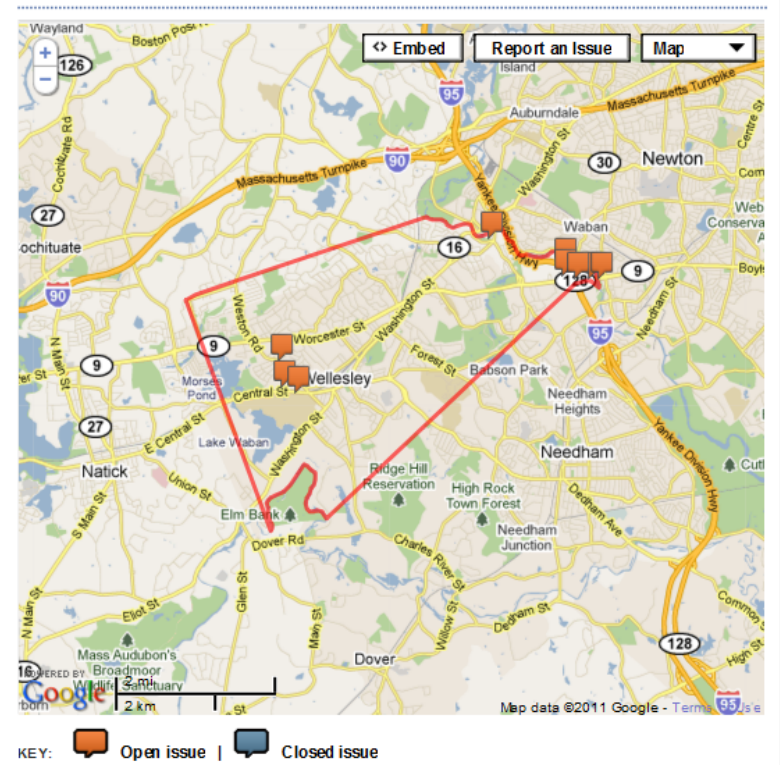

Figure 1: SCF screenshot - Watch area by zip code

\section{How does it work?}

The main reporting tool is a web interface, accessible via http://www.SeeClickFix.com. Citizens enter their zip code (= postal code) and are directed to their neighbourhood with a list of already reported issues, including 
current status and number of votes to fix an issue received from other users. See example for zip code 13210 in Syracuse, NY:

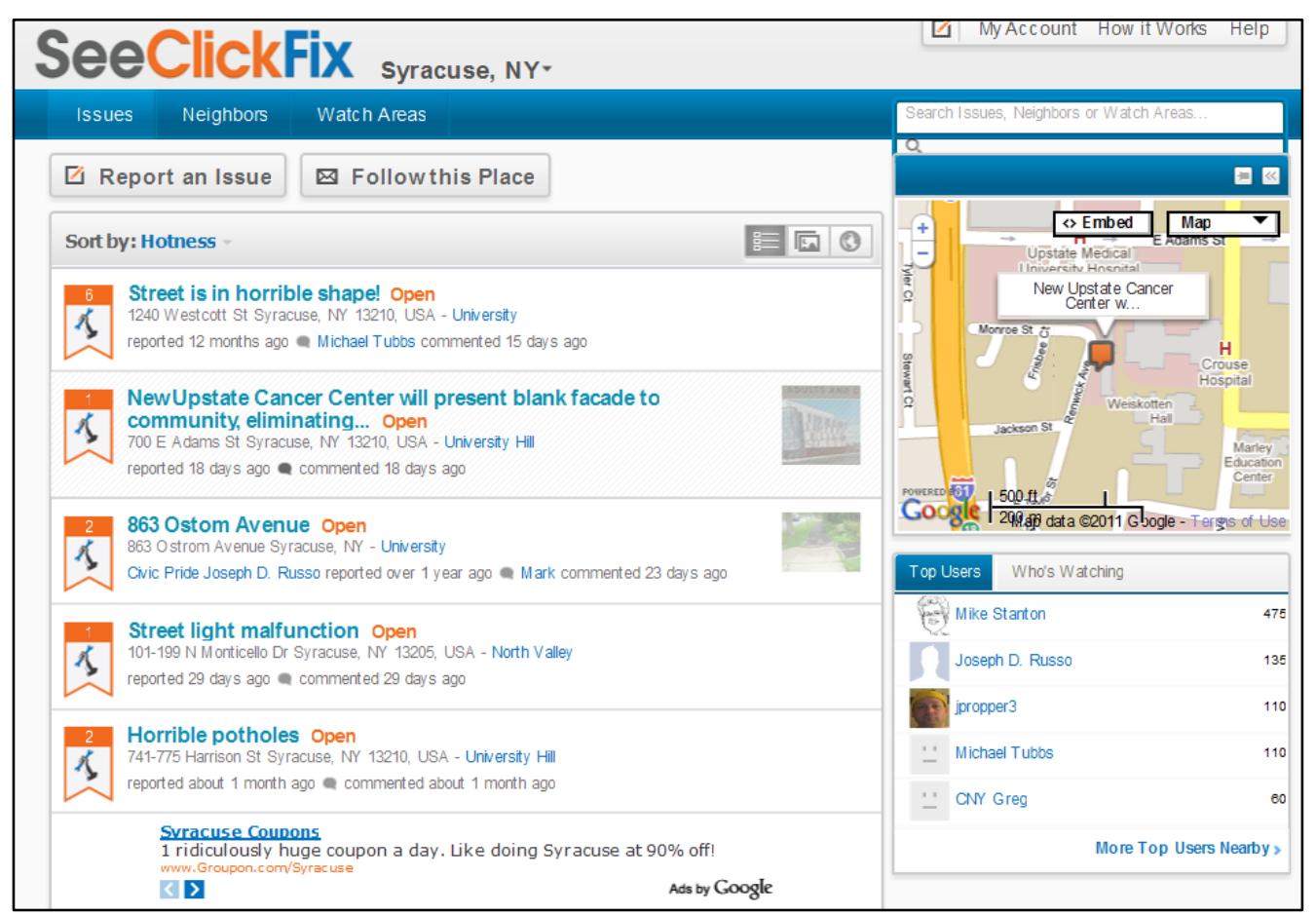

Figure 2: SCF Screenshot - Issues reported by zip code

\subsection{Citizens create an issue report}

Reporting an issue is made easy and citizens can report issues they come across from "where they are". Either via the web interface, or on their commute to work, citizens can take pictures with their cell phones or regular cameras, upload them to SCF, highlight the geographic location, select the type of the issue and add a short description explaining the issue and submit it. Local government receives a standardized email report and can (chose to) submit the issue to the responsible department to start a work order. Other citizens can vote and comment on the reported issues. ii They can vote an issue up or down and receive 'Civic Points' for their participation. The process using an iPhone is outline on the next page. 


\subsection{The role of government in the reporting process}

As outlined above, SeeClickFix is a private initiative of the co-founders and was not initiated by government - and does not mash-up existing government data. SCF has harvested over 16,000 email addresses from local governments that are used to submit alerts as soon a citizen in their local community reports an issue. Almost all American cities have a destination on SCF. Government can chose to opt in and even opt out. Many have updated their email accounts by asking SCF to use a different email address and are actively monitoring complaints. Some have actively opted out of receiving email alerts - stating that their existing citizen reporting systems are providing a valid channel for their citizens to submit reports. Moreover, citizens can

\section{sign up their own local governments.}

Once an issue is reported, public officials can directly respond to the submitted issue. SeeClickFix provides local governments with tools that can be directly connected to their existing work process system and individualized by department (i.e., public works, parks and recreation, police, etc.). As soon as the status of an issue is officially changed by a public servant, notifications are sent out to all the watchers in the community.

The tool really does work for actually solving problems, not just voicing your concerns. And for the most part, has been set favorably in the eyes of government. There's certainly governments that are frustrated, that think that SeeClickFix is a duplicate of their black box web system, where it's clearly not. It's a social platform that ties into government, and if they wanna consume, look at it, they can, uh, and if not, we'll just send 'em an email.

\section{Ben Berkowitz, co-founder SeeClickFix}

The City of New Haven - SCF was founded in New Haven - has adopted the tool as the first pro user. The current Chief Administrative Officer, Robert Smuts, describes the decision making process when the city chose a new reporting tool: 
"We did have something before, but it didn't really take off on either capacity. SeeClickFix meanwhile, after it started up, residents really took to it, and... you know without us really doing anything, you had a huge amount of residents in New Haven who started using this tool. There's the free application where you set up a watch area, and do a key word, and you get the email sent to you. We then set that up for several of our departments itself, or, to funnel the emails to us for like potholes or, you know, tree branches, or whatever the-graffiti, whatever the issue was. Or, he [the co-founder] approached us and convinced us to set them up for ourselves."

\section{Robert Smuts, Chief Administrative Officer, City of New Haven, CT} [Cited with permission]

Other adopters include for example the City of Richmond, VA, that created a separate submission page in the current look and feel of their existing official government website. Citizens are not directly taken to the SCF website, instead they provide a seamless integration as shown on the following screenshot:

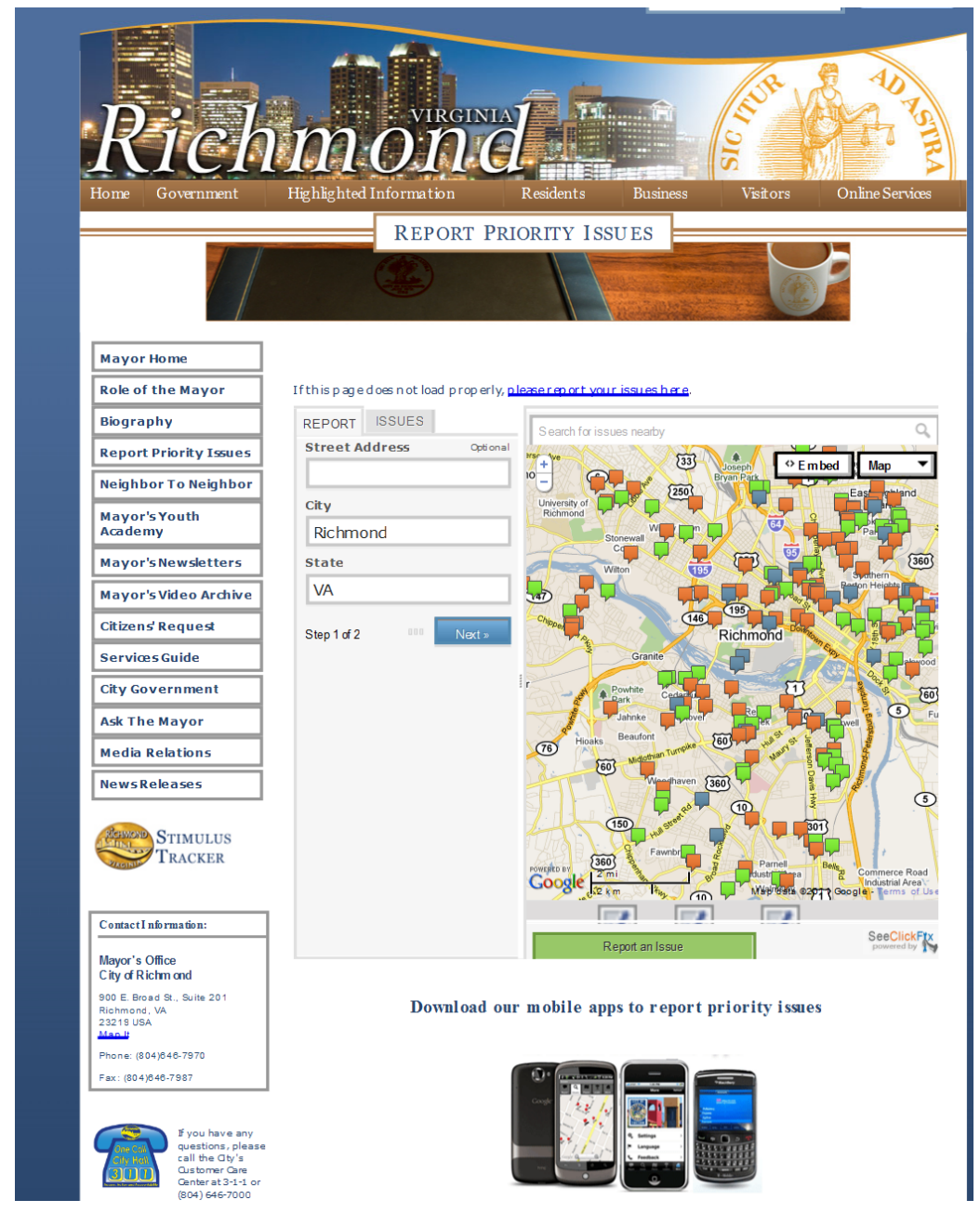

Figure 3: RichmondGov.com - “Citizens' Requests" iii 


\section{Business model}

SeeClickFix was founded as a corner-of-the-desk project without any initial funding. Overtime, the founders won several contests, prizes and angel funding: $a$ contract with the City of Houston, winner of the WeMedia competition, friends and family helped wiht an angel investment run, $S C F$ then took a series $A$ investment from AlphaTech O'Reilly and Omidyar Network to grow the team. ${ }^{\text {iv }}$

The basic email delivery service is free for participating cities. Over time, SCF has introduced a pricing model fro pro, plus and connect categories. The categories differ in their extent of services provided: A Pro user can customize and brand the interface for $\$ 40 /$ month. A Plus user can customize smartphone apps and the reporting tool for $\$ 100 /$ month a Connect user receives an enterprise integration into their existing CRM system in addition to the previous two services. For more information about the current pricing system see http://www.seeclickfix.com/pricing.

\section{Number of users and reported issues}

So far the SeeClickFix web services has several hundred thousand users of which not every visitor actively submits issues - many are using the page to track issues and observe other users' behaviour. In May 2011, the service marked its 100,000 submitted issue. As an example, in the City of New Haven the numbers of issues reported through the SCF service has a far greater volume than the city receives from citizen phone calls or other means. Although it is not possible at this point to draw a direct correlation between the number of issues submitted through either of the existing channels, city managers interviewed for this case state that their anecdotal evidence show that their citizens take more to the easy-to-use online service instead of traditional channels of citizen-government interaction. So far over 20,000 issues were reported in New Haven alone. 


\section{User profile}

The user profile obviously varies across communities and local governments depending on ease of access to the service, population, and distribution of users. What is obvious is that: "There's way more people that come to the site than actually contribute: maybe like 10\% of the people that view the data contribute. There are a lot of people that are just interested in what's going on in their neighborhood, and that's a good thing too. [...] It's pretty well mixed." The service therefore did not only develop into the main reporting service but also offers a pathway to observe how responsive government is to valid issues that are reported in their community. According to the founder, there is a slight tendency towards women over 30 who seem to report more issues than all other contributors.

SCFs targets include all user groups and by providing a wide range of channels to access the service it tries to be highly inclusive. The founders observe the following tendency:

Well, yeah, I mean we'd like everybody to use it. So, we're happy with anybody using it. [...] Socioeconomically, it does tend to start in wealthier communities, but that's not always true, and it tends to spread quickly to less wealthy communities, to the new site, which are pretty evenly distributed in the neighbor-in the city.

\section{Ben Berkowitz, co-founder SeeClickFix}

\section{Dissemination channels}

SeeClickFix does not actively advertise its service, instead the initiative follows a unique distribution model: The service offers a small web widget that can be embedded on local newspaper sites, local television sites, local neighborhood group sites, and Ning sites - another social networking services that allows its users to create their own niche social networking platform. Using local newspapers as a distribution channel helps citizens to report issues from their local news hub - pages 
they visit on a daily basis. The reason for this approach as Berkowitz states is: "We've started with some real thought leaders in local news press like the Boston Globe, and the word traveled through that press. Then we go to conferences and talk to local journalism, and how these kind a issues can really be subject for journalistic endeavors."

As a result many government technology magazines and local newspapers are directly linking to SeeClickFix or are using the web widget, including Soft Company, Inc Magazine, Huffington Post, TechCrunch, ReadWriteWeb, New York Times, Wall Street Journal, Business Insider, Business Week, Forester, Philly.com, SF Gate, and other regional papers, like the Tennessean. See for example the SeeClickFix widget on the Boston Globe's online presence Boston.com:

http://www.boston.com/yourtown/wellesley/seeclickfix/

Other forms of cross-pollination include informal collaborations with NGOs, like "Idle Free Philly" which is an anti idling campaign in Philadelphia. Another Philidelphia-based initiative is running a competition for the most civic points on SeeClickFix. Moreover, many different bicycling groups in Atlanta, like the Atlanta Bicycling Coalition, New Haven, Lansing or Philadelphia and other parts of the country are linking to SeeClickFix. Finally, groups that are interested in parks and recreation are directly linking to the SCF service.

\section{Drivers that lead to the success of SeeClickFix}

Drivers can be analyzed from several different directions and the popularity of the service can not be pinpointed to one exclusive driver, although Ben Berkowitz puts his finger on one aspect that won't go away in the future: "Yeah, a lot a potholes in the world. A lot of broken things that need to be fixed." Citizens will always have 
the need to report issues in their communities and with the ongoing budget crunches in governments around the world, an easy to use low cost product supports this need to talk about things that go wrong in a neighborhood.

The system fits a real need that hasn't been met in local government: for very low set-up costs, local governments can connect to citizens in a very direct way. ${ }^{\mathrm{v}}$ Governments can now respond to individual complaints directly and build a relationship with citizens and use a channel that citizens have chosen to use instead of a one directional push strategy - that has not been accepted by citizens.

Moreover, many local governments are in the process of searching for the right citizen customer relationship management tool, have either already built a system or are dissatisfied with the solutions they were committed to so far. SCF again fits the needs, is easy to adopt and the company works with local government professionals to adapt to their needs.

Online submission services, such as SeeClickFix, fit the current popularity of Government 2.0 online systems - where citizens are willing to take over responsibilities to help improve their environments. Independent of what kind of online service local governments are willing to adopt, submissions of issues are in large percentages coming through web submission services, instead of traditional channels, such as phone calls or even email forms. Take for example the following account:

I just was looking at this. For that month's time, there were 838 instances recorded in our system. Let me see the status on those. Out a those 593 the problem has been solved, others are in process of being worked. Three were taken by phone calls. It looks like 302 came in on the website, and then we have a couple other applications that feed into that. So, see the website's bringing in a lot of these, because people can get on any time, day or night.

Local government professionals are more and more willing to share

responsibilities that were traditionally only in the hands of governments. 
Distributing observations to neighborhood watchers can increase effectiveness and efficiency in government, by replacing some of the inspection roles to the moment when an issue was reported, instead of idle time during regular inspections.

The multi-channel approach of multiple points of entry might help to diffuse some of the digital divide concerns. Providing the service not only on extremely expensive smartphones, but also on newspaper sites, community and nonprofit organizations in form of widgets or on Facebook might ultimately help to increase inclusiveness. When asked, one local government professional responded to the concern: “No, I think it's a good thing. I mean it's just another access point. If we were only using mobile phones, that would be a problem." And he goes on to correct that most of the issues are not submitted through expensive smart phones, but through the website widgets: "Most of our issues come through the, the widgets and not the phones."

While it is clear that adoption is driven by citizen use and not the pro-active use by local governments themselves, most of the interview partners for this case see the clear advantages of the integrated and flexible approach of SeeClickFix:

I like his [Ben Berkowitz's] approach to the mobile applications, where he publishes one application that works for all jurisdictions, and it's really more dynamic, where the user launches the See Click Fix application on their iPhone, they know what jurisdiction, and it reaches out to the service list on their servers, and that's very dynamic, and uses a single application, where some of the other ones like City Source, you have to create the mobile application for each platform, for each jurisdiction. And then if you want to update your service list, you gotta retouch and have that application updated, which I thought was very clunky.

But I liked his architecture of why he was doing. I liked his integration services; he has an API, and if we have our own, in-house technical staff, which we do, we can take that API and integrate it with our own in-house CRM which we already have, and we can do all that for no additional fee, where some of the other service models, they have kind of a low entry point, but if you wanna do any kind of integration, which you really need to do if you wanna really leverage these types of products, um, then they really hit you with that fee to do the interface. And I like Ben's approach where he said: Look, if you want us to do it, we'll charge you and we'll help out, but if you 
have your own staff, you can use the API, and then just have a low like hundred dollar a month fee. So, his was the most affordable model, and it was the most flexible model.

Even though most of the motivation to at least pay attention to their citizens' submissions on SeeClickFix is involuntarily driven by citizen crowdsourcing efforts, we can also observe a lot of personal commitment and an immense sense of civic duty of public managers. Take for example, Raleigh, NC, councilman Bonner Gaylord's use of SeeClickFix. Gaylord started to use SCF for his constituencies and brought his fellow council members, the mayor and at the end city government on board to use SCF. ${ }^{\mathrm{vi}}$ As the announcement states: "The local news site WRAL was so excited by the prospect of enabling open communication between citizens and their governments that they agreed to front the 400/month cost for the City's use of the professional issue tracking and customized smart phone and reporting features." For his initiative, Gaylord received the 2011 Spectrum of Democracy Awards in the category Outstanding Public Servant award. ${ }^{\text {vii }}$

The co-founder and current CEO of SeeClickFix, Ben Berkowitz, has truly become the face of company with an immense visibility. ${ }^{\text {viii }} \mathrm{He}$ is the one speaking to journalists, is known in the government technology press and within the broader Government 2.0 movement as the face of SeeClickFix. ${ }^{\text {ix }}$ This fact might come with disadvantages, but at the moment it looks like it is helping the organization move towards the goal of securing funding and scaling their activities to increase access and sustainability of the service. Ben himself says: 'I don't know if I'm helping or hurting."

Ultimately, the real driver is an overwhelming use of the service among citizens. With additional funding sources SCF might be able to advertise their service directly in those neighbourhoods that might be underserved or reach out to more local 
government officials. One clear signal that will make the business case for the adoption of this service in local government comes from the first Pro User, the City of New Haven in CT:

There was one survey done in New Haven around happiness, satisfaction with government, and I think the end result was that citizens who use SeeClickFix are 15 or $20 \%$ more likely to be happy with their government.

Other interview partners have reported, that they have no way of surveying their citizens and therefore don't know if the service makes a difference. Others have reported that based on their anecdotal evidence, they can say that SCF has made a difference in the way that citizens perceive the interactions with their local government. It might stay unclear until we have comparable studies and results what the exact correlation between uptake of the service, responsiveness of government, effectiveness and efficiency of service provision and increase satisfaction with government transparency, accountability and responsiveness is.

\section{Barriers that might inhibit the adoption of SeeClickFix in local government}

SeeClickFix does not come without any criticism or reluctance on the side of government. Issue reporting or "complaining" is a dicey issue - and especially town hall meetings oftentimes drift into repeated discussions about the same issues: "You have your frequent flyers." This can lead to the attitude "Them vs. Us" or a general understanding that citizens only contact government to complain. ${ }^{\mathrm{x}} \mathrm{SCF}$ tried to counter this tendency by providing a voting and commenting function for each submission, making it easier for government to understand where truly pressing issues occur. 
Nevertheless, there are many local governments that were surprised when they received the unsolicited SCF's standardized emails with citizen reports. Some tried to change the email address that was harvested by SCF and inserted into the system without official verification, so that issues would directly go to the correct corresponding email address. Other try to opt out of the service by contacting SCF to remove their email addresses from the system. Especially in the early days of the service, it appears that SCF was unable to accommodate these requests, which resulted in some negative sentiments among local government officials:

You know, it's unfortunate, because you would like for something like that to really partner with the cities to work together.

Anonymous local government CTO evaluating the use of SeeClickFix.com for his city

Other local governments officials even view SeeClickFix's early focus on citizens instead of on a collaborative partnership with local governments in even stronger terms. In some localities, the report emails go to email accounts that are not monitored, are ignored or marked as spam. The result is that citizens perceive their local governments as unresponsive and in turn public servants were surprised once they heard about their citizen complaints. The service is seen among some nonadopters as a guerrilla tactic. One of the non-adopters and critics of SeeClickFix states:

You can't just throw up a system like that, and then think... Because what it looks like he's doing is trying to make us look bad. On purpose. Where, in fact, we had a system very similar to that already out there for our citizens. And I think it's okay for him to do this; I think it's great to have something that anybody anywhere can get on and report. But what's not great is if you haven't let them know that you've done that, so that then we can tie it into the systems we already have. [...] And so what that does, is it makes the appearance that [city name] does not care. When in fact, we do.

All interview partners stated that they are in the process of exploring a new citizen relationship management system and perceive SCF as the best that is out there, 
even though they criticize some of the initial tactics. They do wish to connect their existing or future services with SCF submission system and integrate the complaints into their public works system.

SeeClickFix - in the business of providing a valuable public service for citizens - sees the main barrier on the side of governments' communication style and ignorance: “Governments that didn't want to communication was a big barrier. You know, you have to take it with a grain of salt when governments get upset with you that you're doing something that they wish they had done."

\section{Measuring the success of the initiative}

Evaluating the success of a start-up initiative is usually done using numbers such as uptake and number of contributors as indicators for early success. As mentioned earlier in this case report, SCF has just recently reached over 100,000 reported issues that $\sim 10 \%$ of their website visitors are submitting. Beyond the numbers of issues that are reported, the website's success really needs to also be measured on the extent to which governments are responding to issues and how many issues are fixed - and reported on SeeClickFix as fixed by government. That means that it's not just the responsiveness of starting a work process and filling a pothole, but also giving citizens the impression that their complaints were heard and that government is willing to create a bi-directional relationship with their constituencies. SCF's success will ultimately be a sign that governments understand the necessity of an active responsiveness cycle and that they are willing to respond using the SCF web platform. As Ben Berkowitz states:

We're sending alerts to 16,000 governments, I think. Probably a thousand of them are pretty responsive. The number is definitely growing. 


\section{Outlook}

SeeClickFix is on its way to establish itself as an independent company. The initial angel funding will help to fund the existing service and support ongoing innovation. In Ben Berkowitz's words, these are some of the additional services that are planned to improve SeeClickFix:

I think we're just gonna keep doing a lot more of the same. We're gonna start doing phone reporting, and we hope to integrate a lot more phone, meaning that someone can do a voiceover, you know, report a pothole by voice, and they'll go into the system.

We're gonna keep improving the tools, and building more tools that help neighbors help each other out. That could mean helping to pay for a project, through citizens, or answering citizens' questions they might have about their community, or, just better connecting people to each other around the public sphere.

We will try to keep making our prices easy for them to do that, and we're building tools that make it easy to integrate. We're will keep working with vendors to hopefully get them to open up, and enable Open 311, or a connection with SeeClickFix.

The service itself seems to attract enough citizens to build a critical mass for governments to receive remarkable input that cannot be ignored. The Government 2.0 movement in the U.S. is just in its second year and many initiatives have manly focused on federal projects initiated as part of the Open Government Initiative. With more citizens forcing governments to respond to their requests online, the ultimate success of SCF will be local governments responsiveness and acceptance of the system as a valid channel of information exchange and a trusted feedback mechanism between citizens and local governments.

One of the main lessons learnt from the adoption and diffusion of this free citizen-driven online submission system is, that governmental non-adopters might never change their attitude towards citizen participation and won't be jumping on the bandwagon. Instead, local governments with enough funding will keep reinventing the wheel and build applications on their own. 


\section{ABOUT THE AUTHOR}

Ines Mergel is an Assistant Professor of Public Administration at the Maxwell School of Citizenship and Public Affairs and The Information Studies School (ischool) at Syracuse University. She was previously a postdoctoral research fellow at Harvard's Kennedy School of Government, Program of Networked Governance and the National Center for Digital Government. Professor Mergel teaches in the Master of Public Administration program courses on Government 2.0, New Media Management in the Public Sector, Networked Governance, and Public Organizations \& Management. Her research interest focuses on informal networks among public managers and their adoption and use of social media technologies in the public sector. In particular, she studies how public managers search, share and reuse knowledge they need to fulfill the mission of their agency.

A native of Germany, Professor Mergel received a B.A. and M.B.A.-equivalent in business economics from the University of Kassel, Germany. She received a Doctor of Business Administration (D.B.A.) in information management from the University of St. Gallen in Switzerland and spent six years as pre- and postdoctoral fellow at Harvard's Kennedy School of Government where she conducted research on public managers' informal social networks and their use of technology to share knowledge.

Professors Mergel's work has been published among others in Public Administration Review, Journal of Public Administration Research and Theory, and American Review of Public Administration. Her thoughts on the use of social media applications in the public sector can be read on her blog: http://inesmergel.wordpress.com.

\section{To contact the authors:}

\section{Ines Mergel}

Assistant Professor

Department of Public Administration

Maxwell School of Citizenship and Public Affairs

Affiliate Assistant Professor of Information Studies

School of Information Systems (ischool)

Syracuse University

215 Eggers Hall

Syracuse, NY 13244

(315) 443-5100

e-mail: iamergel@maxwell.syr.edu

Blog: Social media in the public sector: http://inesmergel.wordpress.com 


\section{Endnotes}

i See Slotnik, D. (2010): News Sites Dabble With a Web Tool for Nudging Local Officials, in: NYT, available online http://www.nytimes.com/2010/01/04/business/media/04click.html, January 3, 2010 .

ii See Fast Company (2010): Fixing a pothole with your iPhone, in: FastCompany, available online: http://www.fastcompany.com/magazine/151/upright-citizensbrigade.html

iii See City of Richmond, Report Priority Issue website with SCF: http://www.richmondgov.com/Mayor/ReportPriorityIssue.aspx

iv See http://techpresident.com/blog-entry/seeclickfix-raises-funds-omidyaroreilly.

v Read more on how SeeClickFix can help local governments: http://radar.oreilly.com/2010/04/crowdsourcing-the-dpw.html See: Raleigh Councilman Bonner Gaylord receives award for bringing SeeClickFix to town, available online: http://seeclickfix.blogspot.com/2011/02/raleigh-councilman-bonnergaylord.html Warner, B. (2011): Center to honor citizens, journals and public servants at 2011 Spectrum of Democracy Awards, available online; http://www.ncvotered.com/releases/2011/2 911 sda_recipients.php See Howard, A. (2010): What is SeeClickFix and Gov2.0, Ben Berkowtiz?, published on GovFresh: available online http://gov20.govfresh.com/what-isseeclickfix-and-gov-2-0-ben-berkowitz/

ix See Kamenetz, Anya (2010): How an army of techies is taking on city hall, in: FastCompany, November 29, 2010: http://www.fastcompany.com/magazine/151/icitizen-bonus.html, and Fretwell, L. (2010: 10 Entrepreneurs chang ing the way government works, Available on GovFresh: http://govfresh.com/2010/04/10-entrepreneurs-changing-theway-government-works/

x See Kennedy, D. (2010: The wisdom of crowdsourcing: Far from the nasty comments found on many sites, projects such as SeeClickFix channel participation in constructive, useful ways, in: The Guardian, available online: http://www.guardian.co.uk/commentisfree/cifamerica/2010/jun/01/crowdsourc ing-internet 